\title{
Sociabilidades, conflitos e circulação na urbanização extensa do Rio de Janeiro: esboço da relação entre mobilidades regionais e transporte coletivo entre Campos, Macaé e Nova Friburgo
}

\author{
Sociability, Conflicts, and Movement in the Large Urbanization of Rio de Janeiro State: An Outline of \\ the Relationship between Regional Mobilities and Public Transport among Campos dos Goytacazes, \\ Macaé, and Nova Friburgo Municipalities, Rio de Janeiro State, Brazil
}

\begin{abstract}
Resumo: Este trabalho tem como principal objetivo descrever e interpretar as sociabilidades envolvidas na circulação por transporte coletivo entre os municípios do Rio de Janeiro, de Campos dos Goytacazes, de Macaé e de Nova Friburgo, com base em observações diretas, em memórias e em etnografias de viagens realizadas entre 2002 e 2018. Parte-se, aqui, do suposto que estes municípios demarcam o perímetro de uma urbanização extensa e difusa, perceptível pela formação de contínuos urbanos ao longo das estradas e da faixa litorânea fluminense, identificável nas estatísticas populacionais e vivenciada em cada município pelo aumento dos problemas urbanos. Se o fenômeno evidencia-se na paisagem, permanece ignorado nas ciências sociais brasileiras, cuja análise da urbanização contemporânea denuncia a perda das sociabilidades, mas não acompanha a formação de novas e a transformação das antigas.
\end{abstract}

Palavras-Chave: Urbanização extensa. Sociabilidades. Mobilidades.

\begin{abstract}
This work has as main objective to describe and interpret the sociability involved in the movement by public transport among the municipalities of Rio de Janeiro, Campos dos Goytacazes, Macaé, and Nova Friburgo, based on direct observations, memories, and travel ethnographies between 2002 and 2018. It is supposed that these municipalities delimit the perimeter of an extensive and diffuse urbanization, perceptible by the formation of urban continuums along the roads and the coast of Rio de Janeiro State, identifiable in population statistics and experienced in each municipality by the increase in urban problems. If the phenomenon is evident in the landscape, it remains ignored in the Brazilian social sciences, which analysis of contemporary urbanization denounces the loss of sociability but does not accompany the formation of new ones and the transformation of old ones.
\end{abstract}

Keywords: Extensive urbanization. Sociability. Mobility.

Hernán Armando Mamani

Bacharel em Ciências Sociais, mestre em Sociologia e doutor em Planejamento Urbano e

Regional (Universidade Federal Fluminense). E-mail: hernanmamani@id.uff.br 


\section{Introdução}

Este trabalho tem como principal objetivo descrever e interpretar as sociabilidades envolvidas na circulação por transporte coletivo entre os municípios do Rio de Janeiro, de Campos dos Goytacazes, de Macaé e de Nova Friburgo, com base em observações diretas, em memórias e em etnografias de viagens realizadas entre 2002 e 2018. Parte-se do suposto, aqui, que estes municípios demarcam o perímetro de uma urbanização extensa e difusa, perceptível na formação e contínuos urbanos ao longo das estradas e da faixa litorânea fluminense, identificável nas estatísticas populacionais e vivenciada em cada município pelo aumento dos problemas urbanos. No entanto, se este fenômeno evidencia-se na paisagem, permanece ignorado pelas ciências sociais brasileiras. De fato, o debate sobre as grandes transformações da morfologia urbana tende a focar-se na problemática da fragmentação socioespacial metropolitana, e reconhece a importância da mobilidade e da fluidez (SANTOS, 1999) nesse processo. Um dos aspectos mais lamentados desta transformação é o de que as antigas sociabilidades/urbanidades tendem a diluir-se, perdendo elementos valorizados da urbanidade da cidade moderna. Prevaleceria, assim, "a sociabilidade mínima da cidade passagem cujo valor crucial é a acessibilidade" (JOSEPH, 1994. p. 5). Tratarse-ia, segundo Ribeiro (1995), de uma urbanização sem urbanidade.
Toma-se distância, aqui, dessa perspectiva. A atenção no artigo recai sobre a circulação regional e o transporte coletivo - elemento central da expansão urbana. Considera-se que os encontros pontuais entre usuários, motoristas, cobradores estabelecem uma trama entre lugares, novas redes de produção e consumo, novos conflitos, novas territorialidades e circuitos nos quais se constroem sociabilidades. Os dados utilizados originam-se da observação, da memória e de anotações etnográficas realizadas durante 18 anos a partir da pesquisa de doutorado e de três pesquisas posteriores (MAMANI, 2004, 2011, 2016, 2017). Quanto à forma de exposição destes dados, depois de uma explanação sobre o quadro teórico, que serve de referência, serão descritos como ocorreu a descoberta dessa urbanização e o registro de suas mudanças ao longo do período alinhavado de forma indiciária (GINZBURG, 1989) e, depois, a sociabilidade dos transportes com base na memória e nas etnografias das viagens realizadas.

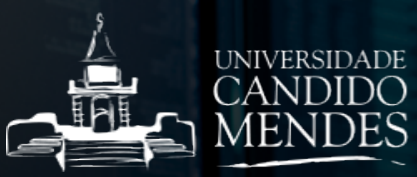




\section{Urbanização, globalização, fragmentação e sociabilidades}

0 debate contemporâneo sobre o processo de urbanização compartilha a convicção de que a dimensão e a intensidade do processo inviabilizam a definição de cidade como uma forma de assentamento ou uma concentração humana em áreas limitadas, em que é possível observar um 'modo urbano de vida' diferenciado do 'modo rural de vida', distribuído em torno de um centro ou uma cidade central que organiza um território (SANTOS, 1999; CASTELLS; BORJA, 1997; GOTTDINER, 1993). As cidades atuais "conformam áreas metropolitanas polinucleadas fora da cidade central. Isto é, regiões urbanizadas não mais organizadas pelas atividades de um centro histórico" (GOTTDINER, 1993, p. 15). São

...grandes aglomerações difusas de funções econômicas e assentamentos econômicos disseminados ao longo de vias de transporte com zonas semirrurais intersticiais, áreas periurbanas incontroladas e serviços desigualmente destruídos repartidos em uma infraestrutura descontínua (CASTELLS; BORJA, 1997, p. 12).

Em lugar da forma compacta da cidade [...] há agora uma população metropolitana distribuída e organizada em áreas regionais, em permanente expansão, que são amorfas na forma, maciços no escopo e hierárquicas em sua escala de organização social (GOTTDINER, 1993. p. 14).

Segundo Gottdiner (1993), ainda, a vida urbana ter-se-ia tornado portátil, capaz de acompanhar a geografia móbil do mercado de trabalho graças ao transporte expresso (autoestradas rápidas, automóvel individual, condomínios residenciais privados e shoppings), permitido a rápida ocupação de áreas, até então não urbanizadas, formando megalópoles de Gotmann (1961), ou de urbanização mundial de Lefebvre (2002).

Já, entre nós, a questão da mudança da morfologia urbana ganhou destaque a partir dos anos 90, relacionada à globalização ao problema da gestão das megacidades (SANTOS, 1991; 2000; CASTELLS; BORJA 1997). $\mathrm{E}$ a atenção dirige-se, particularmente à fragmentação ou dualização, mas tende-se a desconsiderar a extensão geográfica de urbanização. Efetivamente, o foco dado às pesquisas sobre a problemática da urbanização contemporânea tende a se fixar na irrupção de condomínios fechados e shoppings ao longo de vias expressas, à emergência de um padrão fragmentado de expansão metropolitana formado por "microespaços privados, desconectados do seu entorno e conectados diretamente aos centros comerciais e serviços" (LAGO, 2001, p. 1530), que geram a dissolução de modos de vida, da sociabilidade interclassista e da cooperação urbana (RIBERIO, 2003, p. 2).

No caso do Rio de Janeiro, essa urbanização ocorreria, de um lado, como resultado da continuidade do processo de "expansão popular periférica" (LAGO, 2000) e, de outro, da ocorrência de três novos processos, correlatos: a colonização do urbano; a urbanização por enclaves; e a turistificação do território (RIBEIRO, 1995). No primeiro caso, ocorreria a expulsão de moradores e das práticas antigas, promovidas tanto pela introdução de condomínios fechados e seus mecanismos de segurança como pela fragilização do comércio tradicional pela chegada de grandes redes de comércio, de serviços e de lazer concentrados em shoppings. No segundo caso, a produção concentrada de habitação para as classes médias em áreas que, dotadas de amenidades, antes eram ocupadas por segmentos populares. Já no terceiro, tratar-se-ia da transformação do uso do território para fins turísticos. Em todos os casos, afirma-se a perda de sociabilidade, na medida em que se obstrui que a cidade atue como condição de encontro e troca de grupos humanos diversos, propriedade que Lefebvre caracterizou com o termo "direito à cidade".

0 debate brasileiro sobre a urbanização contemporânea toma a mudança morfológica como fragmentação do tecido socioespacial metropolitano, destacando os riscos societários de tal processo, mas não se detém sobre sua extensão geográfica. Chama a atenção, igualmente, que a circulação e a mobilidade não recebem destaque mesmo quando se afirma, com frequência, a importância que as metrópoles adquirem, tanto interna quanto externamente, na dinamização econômica, já que promovem a interconectividade e a fluidez (SANTOS, 1999).

Mas é necessário deter-se sobre o conceito de sociabilidade, tomado nas leituras do debate aqui esboçado como sinônimo de urbanidades ou de cultura urbana. Concordamos com a relação desde que não seja tomada como um epifenômeno econômico. A noção de 
sociabilidade articula dois sentidos de origens distintas (FRUGOLI, 2007): o de Simmel e o de Park. No primeiro caso, a sociabilidade são as formas lúdicas de superar conflitos e de produzir integração e coordenação social (sociação). Assumem a forma atitudes típicas, e correlacionam tanto o mundo social externo quanto a subjetividade individual (atitude blasé). Já no caso de Park, e a Escola de Chicago, o foco se dá na (re)construção de vínculos sociais e morais entre habitantes das diversas áreas da cidade submetidas, permanentemente, a pressões advindas de valorização e desvalorização imobiliária e de processos de crescimento urbano. De modo que os movimentos econômicos desenham diferenças ambientais e funcionais na cidade (áreas naturais), resistida, apropriada e transformada pelos habitantes, que impingem às áreas suas próprias características (áreas morais). Nessa perspectiva, a cidade e suas áreas estão permanentemente em construção - as vizinhanças nascem e morrem, e o agregado total da cidade pode ser descrito como um "mosaico de mundos que se superpõem, mas não se interpenetram" (PARK, 1973). A diversidade de mundos e sua composição dá às cidades riqueza, dinamismo e personalidade e assume a forma de uma superestrutura cultural.

Adiro aqui ao paradigma da cidade em construção (la ville à l'oeuvre), que implica reconhecer o aspecto inacabado da urbanização. Nesse sentido, permito-me, aqui, questionar a tese da urbanização sem urbanidade ou do predomínio de sociabilidades mínimas. Parece cedo ainda para concluir taxativamente a respeito de um fenômeno que não está fechado. Mas é possível esperar também a construção de sociabilidades e redes sociais pautadas sobre uma nova geografia megalopolitana e novos vínculos entre produção, residência e lazer: a produção de um cotidiano regional.

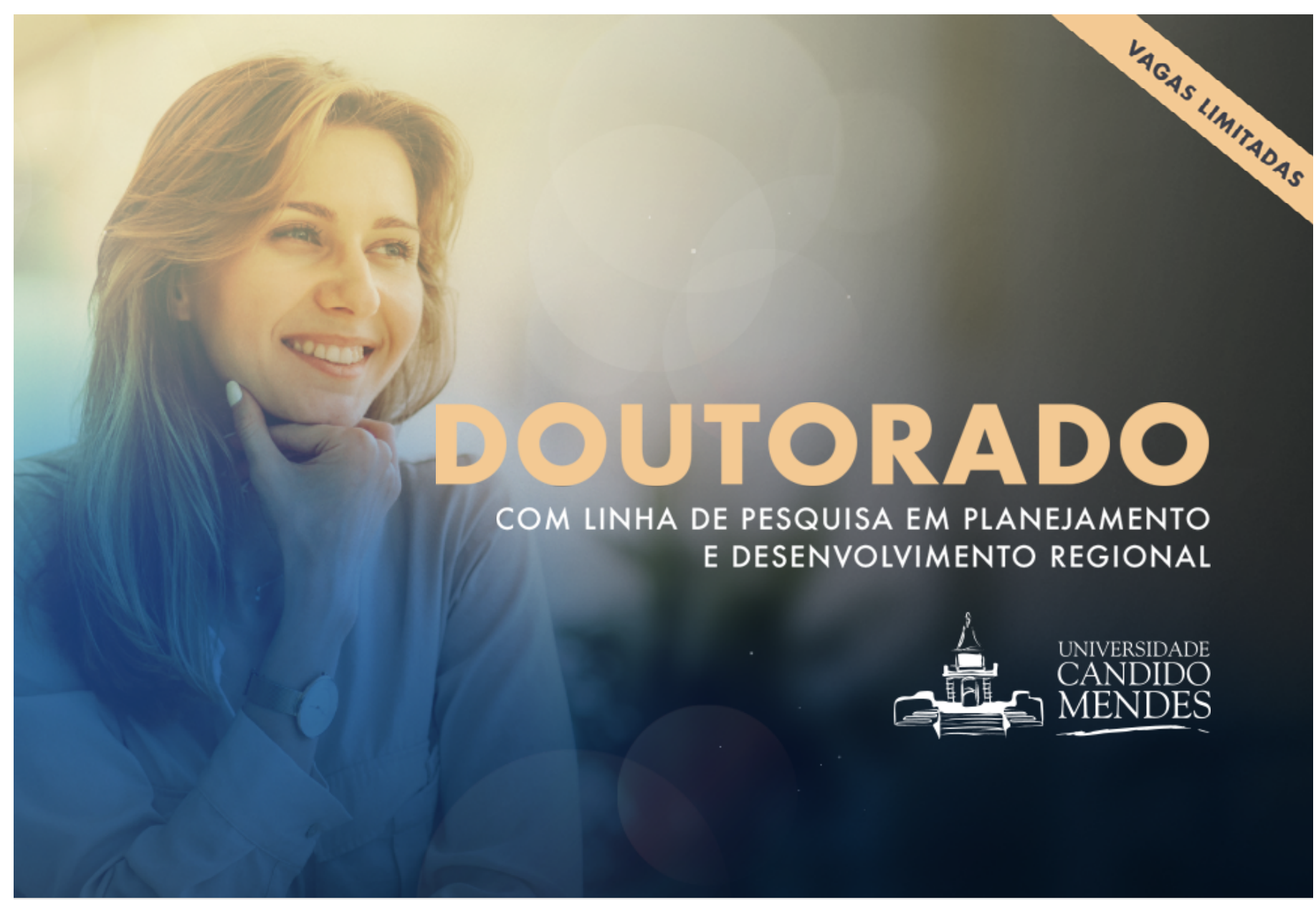




\section{Urbanização regional e mobilidade}

Como já foi mencionado, a expansão da urbanização da metrópole do Rio de Janeiro para além das fronteiras formalmente reconhecidas como Região Metropolitana é um fenômeno poucas vezes tratado, mesmo quando a extensão seja observada e vivenciada na circulação regional periódica de seus habitantes, por motivos de trabalho, educação, saúde ou turismo e lazer. Este fenômeno se impôs a mim como um fato incontornável durante a pesquisa de doutorado (1999-2004). Estudava, então, o transporte informal que naqueles anos expandira-se, de forma exponencial, no Rio de Janeiro. Ao tratar da mobilidade sem um recorte previamente estabelecido, era muito perceptível que a expansão metropolitana configurava uma urbanização diferente da que as noções instituídas de cidade ou de área metropolitana do Rio de Janeiro levavam a pensar.

0 transporte informal permitia deslocar-se a partir do Centro do Rio de Janeiro a qualquer ponto da Região Metropolitana, bem como a municípios distantes mais de 200 km, como Angra dos Reis, Cabo Frio, Búzios, Macaé e Campos. Nessas viagens, era perceptível a formação de contínuos urbanos ao longo das estradas - fora da Região Metropolitana - até Rio Bonito ou em direção a Nova Friburgo, enquanto os municípios da Região dos Lagos apresentavam a fisionomia de uma única cidade, ou de uma periferia metropolitana em rápida ocupação de ruas, loteamentos e construções.

Anos mais tarde, estudos demográficos permitiram-me confirmar o observado de forma direta e acontecendo.
Os trabalhos de Neto e Ajara (2006) foram os primeiros a chamar atenção sobre a expansão das cidades das Baixadas Litorâneas do Rio de Janeiro, fomentada, para as autoras, pela expansão de Macaé, uma cidade global. Mas a magnitude do crescimento dado ao fluxo migratório da Região das Baixadas Litorâneas em direção a Macaé e os municípios próximos não é perceptível estatisticamente, devido à grande migração da Região Metropolitana em direção aos municípios litorâneos (SILVA; CAVENGHI, 2006). Estes trabalhos não consideram, entretanto, os efeitos da mesma expansão sobre os outros municípios do estado - como Campos dos Goytacazes -, de lento crescimento populacional, ou que as cidades menores tenderam a perder população.

Nos últimos 30 anos, a população do estado do Rio de Janeiro cresceu mais de 32\% (1990-2017). A expansão foi muito mais expressiva nas Regiões Metropolitanas e nas Baixadas Litorâneas, que cresceram, respectivamente, no mesmo período, entre $80 \%$ e 141\%. Já no Norte Fluminense, o crescimento foi mais modesto, chegou a 42,22\%. Mas, sem dúvida, o foco desse crescimento se deu nos municípios do entorno de Macaé - que chamarei aqui grande Macaé--, o qual passou de 169.229 habitantes, em 1990, a 455.357 em 2017.

Se o crescimento litorâneo pode ser atribuído à expansão do turismo, na chamada Região dos Lagos, a atração de Macaé deveu-se à expansão da atividade petroleira a partir da segunda metade da década de 90 . Mas o petróleo não explica por si só a integração. É preciso considerar também as transformações econô-

\section{A QUALIDADE DE ENSINO QUE VOCE JÁ GONHECE.}

INSCREVA-SE

\section{AGORA!}

口 PRESENCIAL

口 SEMIPRESENCIAL

口 EAD

www.ucam-campos.br

22 2726-2400 
micas dos municípios em volta: a ruína da indústria metal-mecânica de Nova Friburgo e da produção rural das áreas que não se inserem na produção de hortaliças e legumes, nos anos 90, e a expansão da indústria de confecção e do turismo no $5^{\circ}$ distrito (Lumiar e São Pedro). Igualmente, Campos viu praticamente desaparecer a produção de açúcar, e acompanhou a proliferação de uma economia de serviços, com destaque para o ensino superior e para a expansão da indústria cerâmica. Ao mesmo tempo, no noroeste do estado, declinava a produção agrícola e extrativa - arroz, leite e cimento - proliferando igualmente a economia de serviços.

Certamente a expansão da atividade petrolífera em Macaé (a partir do momento em que se tornou sede da unidade operacional da Petrobras) abriu possibilidades de trabalho para uma ampla gama de profissões e oportunidades para um sem fim de negócios. Assim, os deslocamentos gerados por essa demanda, além da migração, estimulam a mobilidade e tornam o transporte e a circulação um quesito importante do cotidiano regional, realizado por linhas regulares, transporte informal, ônibus e vans fretadas por empresas ou por prefeituras e, mais recentemente, proliferando 0 serviço de 'caronas' obtidas mediante aplicativos.

A mobilidade foi estimulada, já no final dos anos 90, pelo transporte informal, que realizava tanto o transporte local quanto o inter-regional. Vans e carros de lotada fixavam pontos próximo às rodoviárias e estabe- leciam novas redes de circulação e interconexões, mais flexíveis e capilarizadas do que as do transporte regular. Mas o conflito entre informais e empresas regulares não tardou a acontecer, prolongando-se até hoje. 0 estado e cada município adotaram políticas diferenciadas quanto ao transporte informal, que oscilam entre o banimento (Macaé) e a oficialização dos informais (Rio das Ostras e Casimiro de Abreu). Seja como for, em cada ponto de concentração de transporte intermunicipal, estabeleceu-se uma trama de relações entre motoristas, papagaios, cobradores e donos de ponto articulada a uma rede social e regional. Nesses pontos estabelecem-se, também, trocas e laços com usuários - nem sempre efêmeras - e uma relação de concorrência e cooperação com o transporte regular. Quanto aos aplicativos de carona - muito utilizados em dias e horários quando o sistema regular e o informal estão saturados: sextas-feiras e sábados, para sair, domingos e segundas, e à noite -, são um fenômeno muito recente na região, na qual a rede consolidada num ponto não pode ser observada. De todo modo, em cada modalidade de transporte, diferenciam-se as relações de produção, de trabalho e com os usuários e o que parece estimular padrões distintos de sociabilidade que se aproximam nos pontos.

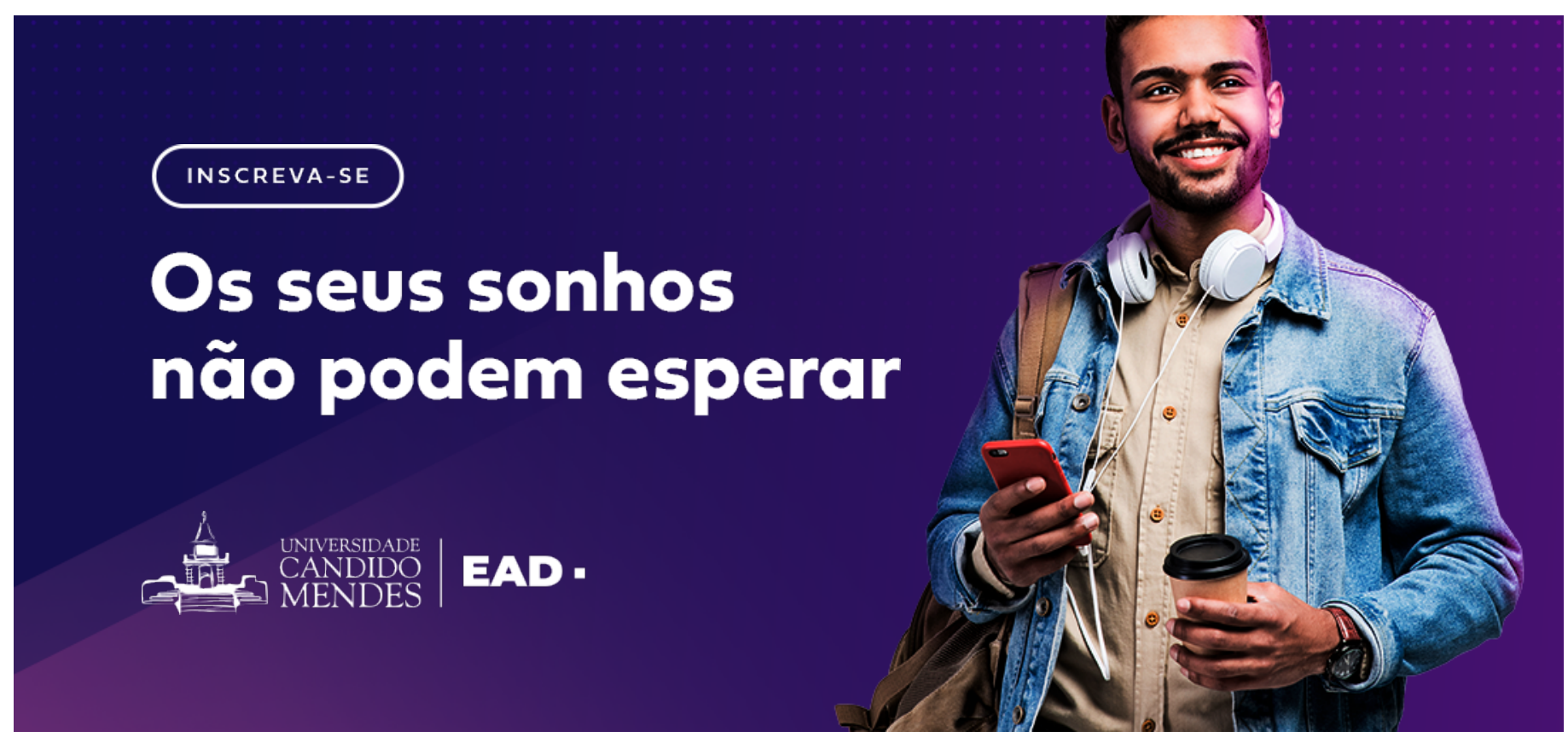




\section{Relatos de circulação}

No início dos anos 1990, ao sair de Niterói, pela BR 101 rumo ao norte do estado, apresentava-se ao viajante uma paisagem pouco urbanizada, repleta de terras devolutas e, alguns quilômetros à frente, terras com uso rural, e alguns núcleos de urbanização em Manilha e no acesso a Itaboraí. A partir daí predominava completamente a paisagem rural e alguns povoados pequenos. Apenas na 'Região dos Lagos' observava-se já uma ocupação urbana mais ampla, mas ainda marcada por áreas nas quais a terra não recebia usos não urbanos.

A cidade de Casimiro de Abreu, por exemplo - hoje centro da circulação regional entre as cidades, parada obrigatória para quem vem de Nova Friburgo em direção ao Rio ou a Campos dos Goytacazes ou para quem vem de Campos, Macaé e Rio das Ostras e se dirige ao Rio de Janeiro ou vice-versa -, era, em 1991, um minúsculo povoado edificado em um dos lados da BR 101, junto a uma antiga estação de trem da Leopoldina. 0 terminal rodoviário, localizado entre a ferrovia e a BR 101, era rodeado por pouquíssimas construções e servia de ponto para os deslocamentos às áreas rurais do município. Quanto às ruas, eram transitadas, principalmente, por cavalos e carroças.

A partir dessa rodoviária, era - e é - possível chegar a Lumiar, no $5^{0}$ distrito do município de Nova Friburgo distante uns 39 km -, e a Sana, no município de Macaé - distante $15 \mathrm{~km}$. As viagens eram feitas por ônibus do tipo urbano - da empresa Líder -, que partiam e retornavam três vezes ao dia. Os motoristas, moradores da região, eram conhecidos por todos os moradores do percurso e estabeleciam uma relação pessoal com eles. Os visitantes que se aventuravam por essas estradas de terra não rompiam aquela rotina.

Sana recebia turistas jovens, de estudantes a hippies, como uma década antes recebia Lumiar. Um único hotel familiar - de Jessé e Josimar - acomodava os viajantes que buscavam mais conforto que os dos campings. 0 atrativo, além da beleza do lugar, eram as cachoeiras, os banhos de rio e a vida rural. Fora a economia do turismo, predominavam atividades pecuárias e rurais, e uma forte economia doméstica - ainda não afetada pela expansão do comércio, dos serviços - e a formação de um mercado de terras para visitantes.

Ao longo da estrada de terra entre Casimiro de Abreu e Sana, existiam alguns restaurantes com acesso a cachoeiras e poços no rio Macaé, que atuavam estritamente nos fins de semana. Já o acesso de Sana até Nova Friburgo era muito desabitado. Três pequenas vilas de quatro ou cinco casas eram atendidas pelos ônibus da Líder: São Romão, Cascata e Campos Elíseos. A estrada de terra sofria com as chuvas de verão, e as interrupções eram muito frequentes.

Ainda em 1997, Casimiro de Abreu permanecia rural e pequena, e o movimento de veículos na BR 101 era muito baixo, pouquíssimo transitada se comparado ao

MES T R A D 0

PESQUISA OPERACIONAL E INTELIGÊNCIA COMPUTACIONAL LINHA DE PESQUISA EM SAÚDE

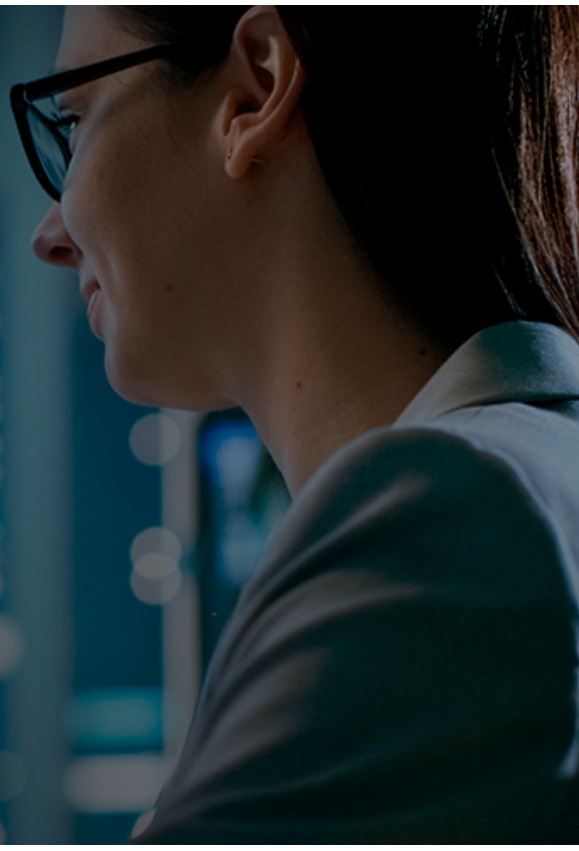


volume atual, e os trens ainda circulavam. Igualmente, Rio das Ostras, distante $30 \mathrm{~km}$, permanecia como vila pequena em torno de sua praça e separada de Barra de São João (no município de Casimiro de Abreu) e de Tamoios (no município de Cabo Frio) por $10 \mathrm{~km}$ de grandes áreas descampadas. Mas ao longo das estradas, observava-se já um grande número de outdoors, que publicitavam loteamentos. Certamente havia muitas casas em construção, distantes e isoladas, sem que houvesse nem condomínios fechados nem shoppings. 0 turismo propriamente dito concentrava-se em Búzios, Cabo Frio e Arraial do Cabo. Quanto ao transporte informal, já existia, mas não era perceptível nem tratado como problema, o que veio a acontecer na década seguinte.

Entre 1997 e 1998, grande parte da ocupação das Baixadas Litorâneas, próximas a Macaé, parecia ao viajante uma ocupação "turística", estimulada por loteamento e autoconstrução de uma segunda residência. Essa expansão evidenciava-se ao circular nas estradas litorâneas - quando possível - entre Búzios, Cabo Frio, Arraial do Cabo, Araruama, Saquarema, Maricá e Niterói. Naqueles anos, desenhava-se já a ocupação residencial quase completa daquelas áreas, refreada apenas pela presença de reservas ou áreas sem estradas.

A interpretação turística parecia-me plausível naquela época, dado que eu mesmo conhecia essas áreas turisticamente, e não era possível notar a influência de Macaé sobre o processo, muito embora eu já tivesse alguns conhecidos que haviam se mudado para Macaé e Rio das Ostras e apresentavam aqueles municípios como um mundo de oportunidades para a construção, o comércio e atividades de apoio à economia do petróleo. Mas somente conheci Macaé, como de resto o Norte e o Noroeste Fluminense, quando passei a trabaIhar em Macaé, enquanto fazia a pesquisa doutoral.

De fato, a partir de 2002, eu mesmo passei a partici- par dos movimentos pendulares casa-trabalho entre Macaé e Rio de Janeiro. Trabalhava no Laboratório de Engenharia de Exploração de Petróleo da Universidade Estadual do Norte Fluminense Darcy Ribeiro (LENEP/ UENF) como professor substituto.

Esta área distava $10 \mathrm{~km}$ do Centro de Macaé e outros tantos do Centro de Rio das Ostras, mas era muito melhor servida de transportes a partir de Rio das Ostras do que de Macaé, cujo transporte coletivo era velho, demorado e irregular. Aliás, a mobilidade entre todos os municípios era atendida com bastante eficiência por vans, kombis e carros de lotada.

Sendo alguém que visitava a cidade exclusivamente para trabalhar, devia ter cuidado para chegar a tempo vindo do Rio de Janeiro. Quer dizer, devia considerar o tempo de viagem de longa distância e a coordenação adequada ente o transporte de longa distância e o transporte local para chegar a tempo. E no retorno, buscar um modo de regressar tão rapidamente quanto possível. A opção do ônibus urbano até a rodoviária de Macaé era demorada, mas, uma vez lá, podia escolher entre os ônibus e a lotada. A opção por Rio das Ostras exigia que caminhasse $1 \mathrm{~km}$ até a estrada RJ 106 e que conseguisse uma van com vaga, o que, dependendo do horário, era difícil.

No meu primeiro dia de regresso, haviam me informado que por ali passavam ônibus para o Rio de Janeiro, e que seria fácil retornar. Com base nessa informação, caminhei até a estrada no horário informado e esperei. De fato, no horário, um ônibus da Viação 1001 da linha Macaé-Rio, via Araruama - parou e iniciei o retorno. Nessa viagem, voltei a passar por trechos que visitara cinco anos antes, e descobri a continuidade da ocupação urbana. Desenhava-se uma conurbação entre Macaé e Rio das Ostras, cujo Centro vivia, como até hoje, engarrafado. E, a partir daí, toda a orla, exceto os últimos $4 \mathrm{~km}$ da praia rasa - onde se localiza uma reserva da Marinha, na entrada de Búzios, o trevo da 
RJ 106 e RJ 102 -, encontrava-se num processo de ocupação periférica.

A paisagem de construções e ruas de terra se afastavam da estrada principal sem penetrarem muito na Baixada. Sobrados com uso comercial no andar térreo e no andar superior com uso residencial proliferavam ao longo da estrada. 0 ônibus intermunicipal atuava como ônibus urbano, parando a cada ponto. Desse modo, uma viagem que duraria pouco mais de duas horas e meia levava sete fatigantes horas... Não usei mais essa linha.

A opção era então chegar por transporte informal por Rio das Ostras e retornar ao Rio por Macaé nas linhas diretas que circulavam pela BR 101. Nesse caso, ia até a vila de Imboassica para tomar um ônibus velho e 40 minutos depois chegar à rodoviária, onde uma multidão de trabalhadores offshore buscavam, como eu, partir rápido.

Em Macaé, como no Rio de Janeiro ou em Campos dos Goytacazes, ao lado da rodoviária, "papagaios" informavam em altos brados os destinos para os quais carros de lotada se destinavam: Rio, Niterói, Campos... Mas nesta cidade, a rodoviária estava rodeada de bares, onde grupos de homens tomavam cerveja, conversavam com garotas de programa ou simplesmente aguardavam a partida.

Esse vai e vem, que repeti semanalmente entre 2002 e 2003 e que se expandiu, a partir de 2004, para Campos dos Goytacazes, me permitiu conhecer a rotina das cidades e acompanhar suas mudanças no tempo. Assim, até 2007, a circulação entre Macaé e Rio das Ostras, Barra de São João, Tamoios e Casimiro de Abreu era predominantemente informal. A partir daquele ano, Macaé licitou o sistema de transporte, implementou o sistema integrado e baniu do município o transporte informal. Nos outros municípios, o transporte informal permaneceu regular fazendo a circulação interna. De todo modo, e apesar da repressão, carros particulares continuaram fazendo 'lotadas' entre as cidades, apenas dissimulavam sua presença.

Como a partir de 2004 comecei a viajar com mais frequência de Macaé para o norte, pude observar, também, que o mesmo padrão de ocupação urbana das áreas laterais da estrada RJ 106 continuava além do Centro de Macaé e do rio homônimo em loteamentos e favelas numa extensão de mais de $10 \mathrm{~km}$. Embora se interrompesse como contínuo, a expansão de Macaé impactava os municípios próximos: Carapebus, Conceição de Macabu e Quissamã.
Aliás, impactou o valor da terra e impulsionou 0 mercado de terras urbanas em todos os municípios em volta. A área sul de Macaé tornou-se mais valorizada, tanto mais cara quanto mais próxima do mar. 0 mesmo ocorreu com Rio das Ostras e com Tamoios. Já em Casimiro de Abreu, a sede do município expandiu-se tanto em termos habitacionais quanto comerciais, e as pequenas vilas ao longo da estrada de ferro, com grandes casas de telhas claras e janelas de blindex, mostravam-se do mesmo estilo das construídas nas praias. Já o caminho de Sana e Nova Friburgo mudou substancialmente a partir da pavimentação da RJ 142 em 2007. Com a melhoria do acesso, além de surgirem grandes casas e sítios na beira do rio Macaé, aumentou o número de loteamentos. Sana e Lumiar consolidaram-se como vilas turísticas. Proliferaram os resorts e pousadas luxuosas na região, e os pequenos vilarejos de São Romão, Cascata e Campos Elíseos cresceram significativamente.

Quanto ao transporte formal intermunicipal, intensificaram-se os serviços entre as cidades de modo tal que Campos e Macaé, em janeiro de 2010, eram os mais interconectados do estado com a cidade do Rio de Janeiro. Para Macaé, ocorriam 80 viagens diárias e ofereciam-se 2400 vagas, enquanto, para Campos, 23 viagens ofereciam 920 vagas diárias (Mamani, 2011). Igualmente, Nova Friburgo passou a ter serviços regulares, conectando-se a Macaé e a Rio das Ostras, com cinco viagens diárias e 200 vagas depois que a RJ142 (estrada Serra-mar) foi asfaltada em 2007.

Obviamente esta contabilidade superficial não consegue levar em conta as viagens de carros particulares nem os fretamentos de ônibus de trabalhadores que diariamente se deslocam, nem dos estudantes que se dirigem às universidades. Por outro lado, o município de Campos não foi diretamente afetado pela expansão costeira da urbanização, mas integra-se fortemente, sem dúvida, à circulação e à mobilidade regionais. 


\section{Sociabilidade e circulação}

Toda viagem tem uma dimensão de aventura. Como apontado por Simmel (1998), ela constitui um corte na continuidade da vida, um lapso, no qual todas as atitudes voltam-se exclusivamente para o presente. Assim, os pequenos percursos diários tenderiam a ser esquecidos por não serem particularmente significantes, enquanto as grandes viagens tenderiam a ser recordadas, dada sua singularidade. Mas, ao tratar-se do transporte coletivo e do transporte informal, a magnitude da aventura intensifica-se pelas possibilidades de encontro (e de conflitos) postos.

Certamente, quando considerados os espaços relacionados ao viajar, é possível identificar várias formas de exposição dos passageiros aos riscos e aos encontros inesperados. Nesse sentido, os tipos de viagem, 0 veículo e os momentos de partida e chegada podem ser analisados utilizando a oposição entre atitude blasé e atitude aventureira, entre cálculo e entrega ao risco, que, em termos de espaço, corresponde à oposição entre espaços impessoais $x$ pessoais, cosmopolitas $x$ privados. As rodoviárias, os pontos de parada e os veículos em si constituem espaços nos quais predominam tensões e certos modos de tratá-las. Espaços de sociabilidades típicas de que aqui trataremos.

As rodoviárias de uma cidade e seu entorno são lugares de máximo cosmopolitismo e de maior risco, e os pontos de chegada e partida de veículos e o inte- rior das rodoviárias, lugares que proporcionam uma proteção relativa. Nesse sentido, a Rodoviária Novo Rio, na cidade do Rio de Janeiro, constitui exemplo extremo. Localizada numa área bastante degradada da cidade - mesmo após as obras das Olimpíadas -, 0 exterior do terminal é extremamente movimentado. Convergem tramways, ônibus urbanos, taxis e pessoas que chegam e que saem. No seu entorno, uma rede intrincada de viadutos e ruas dá abrigo aos pontos de lotada intermunicipais, aos carros que fazem carona e a numerosíssimos ambulantes. As portas do terminal são particularmente confusas: quem chega ou sai é abordado por uma infinidade de propostas. Quem sai ou quem entra o faz de forma furtiva, enquanto recebe propostas de taxi, de engraxates, de "papagaios" e ao mesmo tempo busca se orientar. 0 interior contrasta com o exterior por ser mais protegido, com suas fileiras de bancos, com seu comércio e seus guichês, sempre cheios, com filas e pessoas buscando informação, e a praça de alimentação que lembra a de um shopping. 0 interior da rodoviária é um lugar de anonimato, predominam as relações calculadamente impessoais e a atitude blasé, enquanto o exterior representa o risco, a furtividade e o caráter aventuroso da viagem.

A escolha pelo informal tem uma dimensão de aleatoriedade. Certamente a pressa em chegar ao destino e o preço inferior ao do ônibus tendem a pesar na escoIha, mas é sem dúvida a relação com o "papagaio" que define a opção. 0 "papagaio" é o agente de informação e negociação, e o diálogo com ele precipita a decisão.

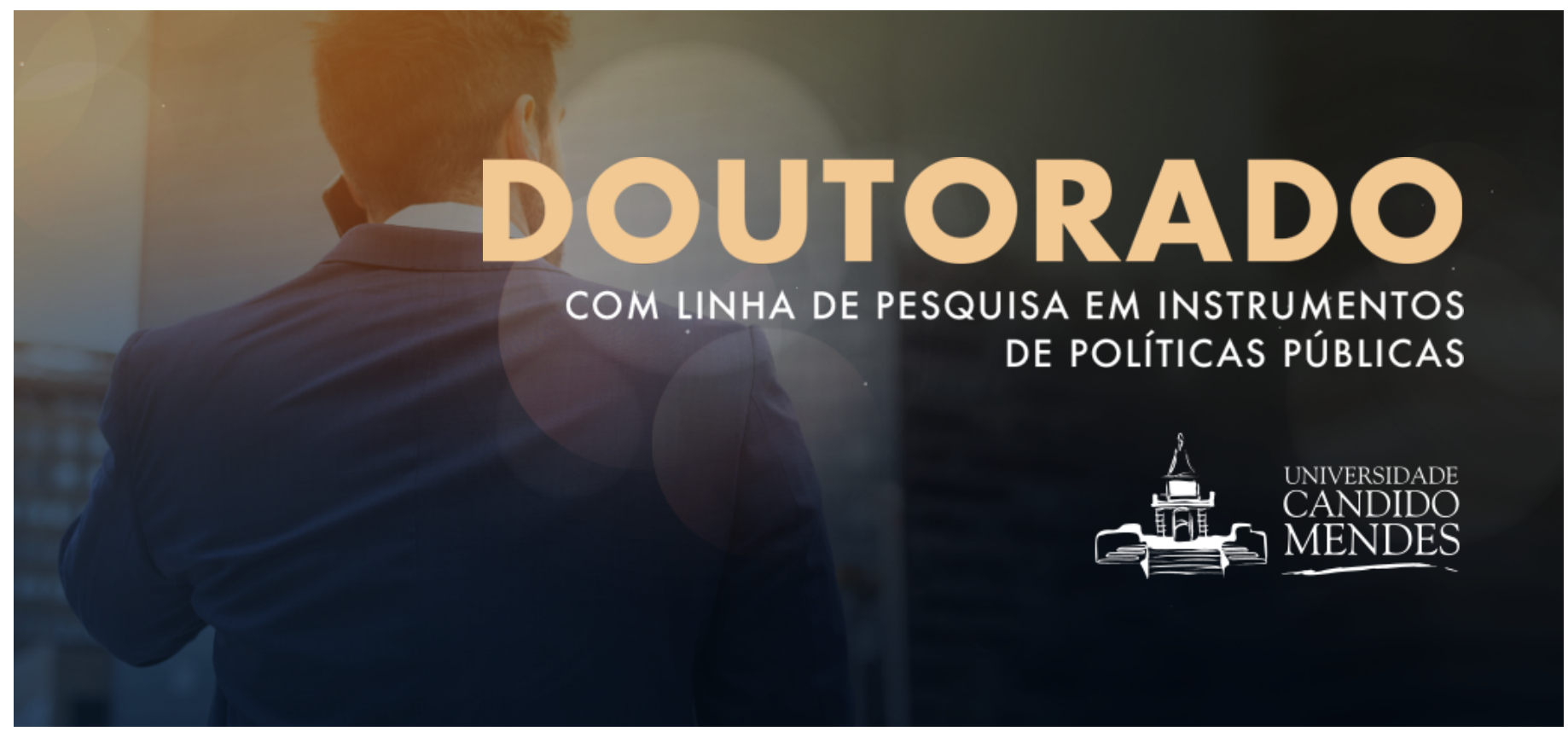


É ele quem - uma vez decidido usar o transporte informal - guia os passageiros em segurança até o veículo e os põe em contato com o motorista, que informa da demora provável, que negocia as particularidades da viagem. A partir desse momento, os passageiros aguardam em lugares improvisados para tal fim numa esquina, embaixo de uma marquise comercial ou de um viaduto, sempre próximos dos motoristas e fiscais que formam um círculo separado, em que predomina uma sociabilidade profissional - misto de troca de informações e 'zoação' masculina.

Próximos e ao mesmo tempo distantes entre si, os passageiros aguardam com pouca interação, no máximo comentários sobre a demora e às vezes reclamações. Finalmente, quando o veículo 'lota', ocorre um último conflito de silenciosa hostilidade. Quem chegou primeiro tende a ocupar o banco do carona; o segundo, o banco traseiro à esquerda; e os dois últimos buscam evitar se sentar no meio. Sem falar daquele que, ao se aproximar primeiro da porta da direita, senta... e a viagem começa. Quando o veículo inicia o movimento, as atitudes mudam e o vínculo torna-se pessoal, e começa a conversa na qual o motorista é uma sorte de mestre de cerimônias. Esse vínculo pessoal (carisma) abre uma conversa franca sobre si e sobre a vida, a profissão, os lugares, a família. A conversa que ocorre como que 'fazendo sala' é uma sorte de 'sinceramento' entre estrangeiros. E o mesmo acontece em todas as modalidades de transporte informal realizado por carros, inclusive o BlaBlaCar.

\section{Atitude comercial $\mathbf{x}$ doméstica}

A identificação encontra seu ápice quando os passageiros trabalham juntos para superar ou solucionar algumas dificuldades durante a viagem. Assim, por exemplo, em 2002, numa das muitas experiências de regresso de Macaé ao Rio de Janeiro, fui conduzido pelo "papagaio" a um Fiat Dobló novo, cujo motorista era jovem. Tinha estudado publicidade, tinha um grupo de música e aspirava a gravar discos - cujo demo publicitava no caminho. Era um rapaz simpático e solícito. Em algum ponto da estrada, próximo da cidade de Silva Jardim, um pneu furou. Naquele veículo, o estepe ficava preso num compartimento inferior, que o motorista não sabia abrir. Era final de tarde, e a estrada estava deserta e havia cada vez menos luz. Aos poucos, todos os passageiros foram assumindo funções. Uns se revezavam na sinalização, outros tentavam descobrir como abrir o compartimento, até finalmente conseguir e prosseguir.

Vários anos mais tarde, em 2006 - horas antes do primeiro jogo do Brasil na Copa daquele ano -, buscava eu uma maneira de chegar rápido ao Rio de Janeiro partindo de Campos dos Goytacazes. Os ônibus estavam sem vaga e procurei uma lotada. Fui o último a chegar, de modo que o carro saiu logo. A viagem começou como sempre, com relatos. 0 motorista vinha do transporte de caminhões de cana de açúcar (caminhões-gaiola), estava sem trabalho e atuava, no momento, como motorista auxiliar daquele carro. Tudo seguia perfeitamente até atravessar a ponte sobre o rio Macaé - no km 140 da BR 101, sentido Rio. 0 veículo ficou sem combustível. 0 motorista culpou o proprietário por não tê-lo informado de que o carro estava com pouco gás. Não era possível pedir apoio a ninguém, dado que, naquele ponto da estrada, não havia sinal de celular. 0 motorista pegou então uma carona com um carro do ponto que passava em sentido contrário e retornou com gasolina do posto, que distava $6 \mathrm{~km}$. Com isso seria possível chegar até Rio das Ostras onde abasteceria com GNV. Mas o combustível não foi suficiente, e o carro parou novamente a $1 \mathrm{~km}$ do posto. A partir daí, todos os homens empurramos. Não houve protesto, todos queríamos chegar ao Rio a tempo de ver o jogo. É importante frisar que o fato de não ter reclamações sugere que a viagem não era vista como uma relação contratual. Isso difere muito de situações nas quais um ônibus para na estrada por uma pane. Nesse caso, tanto o motorista quanto os passageiros esperam da empresa a rápida solução. E, ainda, a empresa arrisca ser acionada judicialmente.

Pude observar a mesma relação 'doméstica' numa outra oportunidade, no início de 2007, no trajeto Casimiro de Abreu-Lumiar (Nova Friburgo). Naqueles anos, a estrada estava sendo pavimentada, e o serviço de ônibus regulares desapareceu. A única possibilidade de subir a serra era usando os serviços de uma kombi, que partia três vezes ao dia. Tinha viajado já algumas vezes na parte da manhã, mas, na ocasião, viajei à tarde, numa sexta-feira. 0 ponto $-100 \mathrm{~m}$ depois da rodoviária de Casimiro de Abreu, à beira da BR 101 - estava lotado às 18h, hora da partida. Ao chegar a hora de subir no veículo, não havia lugar para todos nem sentados nem em pé. Reclamei com o motorista, que me respondeu que se não quisesse não viajasse. Precisava viajar, de modo que a partida se deu comigo e cinco pessoas no porta-malas. Dez quilômetros à frente, as pessoas começaram a descer e a viagem foi ficando mais confortável.

Gostaria de frisar, com base nessa experiência extrema, que a sociabilidade tecida no interior do veículo particular (mesmo em se tratando de serviços do BlaBlaCar) assume a forma de sociabilidade doméstica, de visita ou comensais, em particular, na qual todos 'fazem sala" 
e na qual todos estão dispostos a colaborar em caso de dificuldades. Embora se trate de um serviço pago, o transporte não é vivenciado como uma relação comercial. Isso contrasta com o serviço de ônibus, em que todo o processo é visto de forma comercial, portanto, mais distante e calculado, em cujas viagens predomina o distanciamento entre os passageiros.

\section{Os pontos}

Quanto às paradas, observa-se a mesma diferenciação. As empresas têm seus pontos específicos. Geralmente grandes restaurantes. No caso estudado, a Viação 1001 para num grande restaurante chamado Oasis, pouco depois de Casimiro de Abreu. 0 trato nesses casos é impessoal. Já no do transporte informal, simultaneamente à sua expansão, proliferaram restaurantes à beira da BR101, que evocavam, com nomes, arquitetura, decoração e instalações, sua condição rural. Os carros com destino a Macaé paravam preferencialmente num deles, chamado Sabor Rural. Já os carros com destino a Campos paravam em Casimiro, próximo à rodoviária. Na circulação para Nova Friburgo, no início da década de 2000, instalou-se, na encruzilhada da BR 101 com a RJ 142, uma lanchonete - anexa a um restaurante e pousada homônima -, que se tornou parada de todos os que descem ou sobem a serra.

A emergência desses novos pontos de parada eclipsou as paradas antigas, genuinamente rurais e não temáticas, ao menos ao longo da RJ 142. Nesses pontos, tece-se uma forte relação entre motoristas e atendentes - jocoso e ao mesmo tempo profissional. Porém, a relação com os passageiros é mais distante, mas, com o tempo, torna-se mais pessoal. Esses pontos são também lugares de encontro das elites políticas e econômicas locais. Em grandes traços, há principal diferença nas atitudes no transporte formal e no informal. 0 transporte formal se refere à predominância de atitudes distantes e impessoais estabelecidas, principalmente, com base em critérios comerciais. No transporte informal, predominam as relações personalizadas, com base em critérios domésticos. Mas a personalização e a dimensão carismática da personalidade é, também, necessária para a implantação de serviços formais desconhecidos ou não usuais. Assim, quando, no início de 2008, a Viação 1001 inaugurou serviços regulares na RJ 142, entre Nova Friburgo e Macaé, destinou para a linha motoristas nativos da região, que paravam em cada ponto, informando, gentilmente, sobre o serviço e tratando cada passageiro com simpatia e deferência. Mas uma vez implantada a linha e eliminada a concorrência, "rotinizou-se o carisma"1 e eliminou-se a simpatia no trato pessoal. Faço uso livre do conceito weberiano.

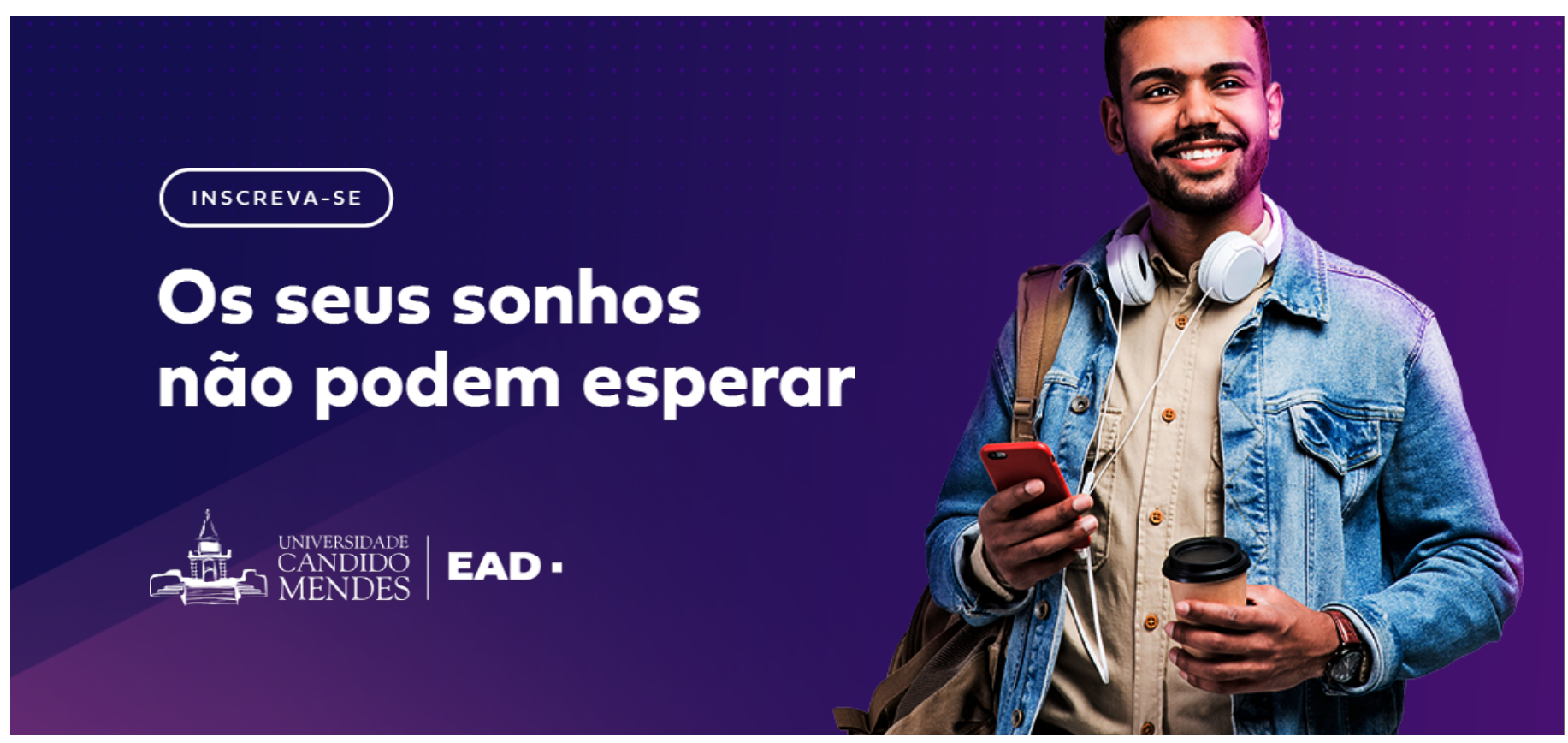




\section{Novos aplicativos (BlaBlaCar)}

Dentro do quadro analítico aqui esboçado, a carona talvez seja a modalidade de viagem que mais corresponda à aventura e a uma atitude aventureira. Mas, em princípio, os novos aplicativos parecem destoar desta interpretação. 0 debate recente em torno deles tem focado os aplicativos urbanos - o Uber em particular - e sua concorrência com os taxis e menos sobre outros aplicativos como o 99 Pop ou o Urbano. Mas - BlaBlaCar é uma empresa e um aplicativo que não atua no mesmo ramo. Trata-se de um empreendimento francês, que data de 2006, introduzido no Brasil em 2015. Seu objetivo é o de promover e otimizar caronas intermunicipais, barateando os custos das viagens e incrementando o uso de combustível, e possibilitar, mediante um sistema, cadastros e avaliações mútuas, num ambiente de confiança entre os participantes.

Segundo os critérios que utilizamos aqui, o aplicativo oferece um clima de segurança e de confiança, dado que todos os participantes são cadastrados e avaliados; não há anonimato. Em princípio, elimina a incerteza e a impossibilidade de coordenação temporal das viagens (típica do transporte informal), a insegurança e as tensões dos arredores das rodoviárias. Cobrando preços equivalentes ao transporte informal, o BlaBlaCar personaliza os serviços e permite um ajustamento maior entre o passageiro e o motorista em termos de local e horários, ao menos nas áreas nas quais há maior circulação - o eixo Campos-Macaé-Rio -, e menor nos caminhos transversais.
Quanto à sociabilidade durante a viagem, segue as mesmas características do transporte informal; o interior é um espaço doméstico, o motorista, um anfitrião. E igualmente nas conversas, ocorre um diálogo sincero para com o estrangeiro.

Neste transporte, há dois tipos de motoristas: os 'caroneiros' profissionais e os que viajam regulamente por outros motivos, por trabalho, negócios ou lazer. Os primeiros utilizam vários aplicativos na circulação local e regional. Por exemplo, circulam com Uber, em Campos ou Macaé, e BlaBlaCar ao retornarem de corridas longas e, nesses casos, atuam como lotadas. Os segundos são viajantes de comércio ou pessoas que viajam regularmente entre municípios e oferecem caronas para diminuir custos.

Como se vê, a introdução de aplicativos de carona não diminui o caráter de aventura das viagens nem a comunicação estabelecida no interior dos veículos. Contribui para a diminuição dos riscos e aumenta a racionalidade da circulação regional, mas diminui com isso o cosmopolitismo inerente à viagem.

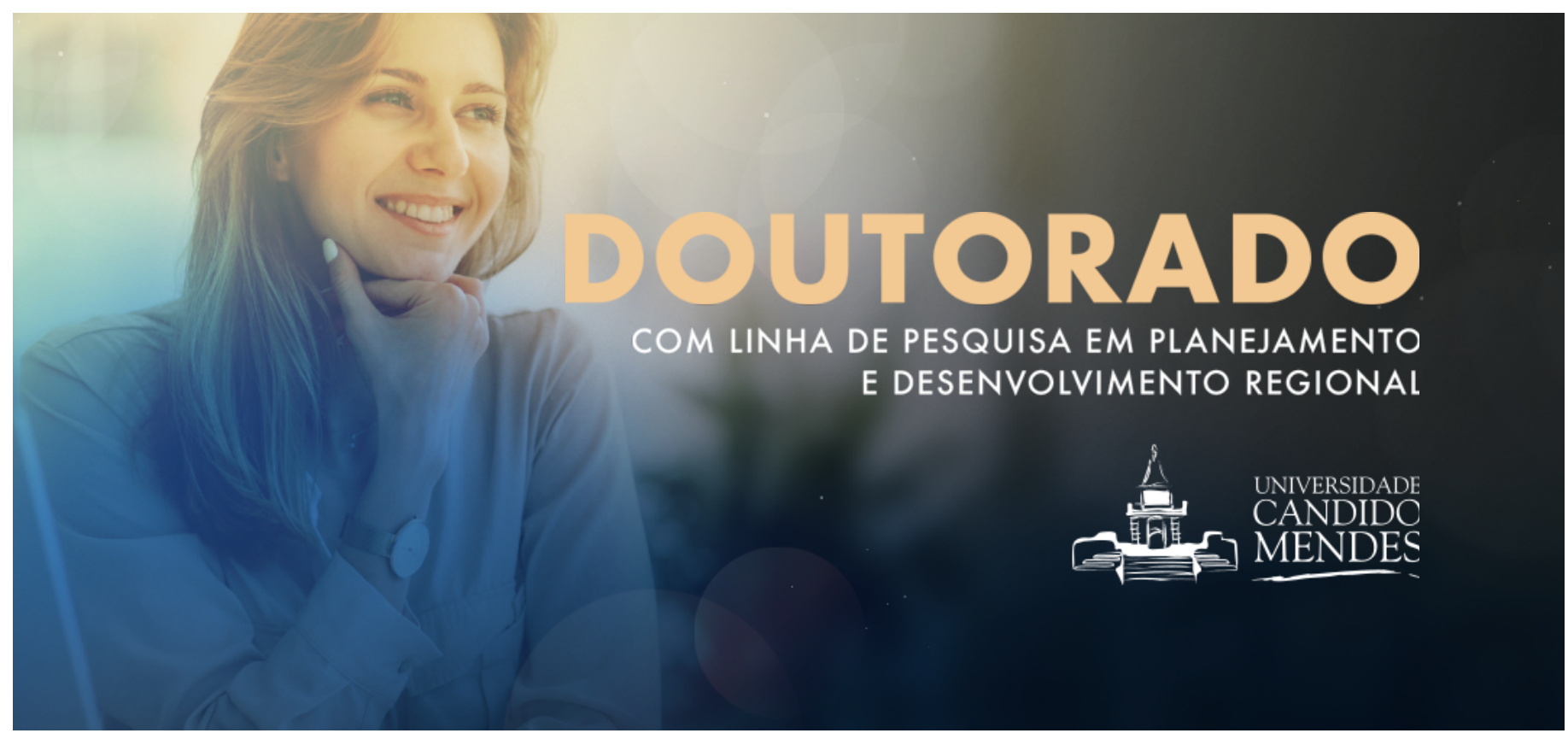




\section{Conclusão}

Os dados apresentados reforçam a hipótese de megalopolização ou urbanização extensa do Rio de Janeiro. Mas a predominância da causa econômica tomada pelos estudos, que nos servem de referência como indiscutíveis, não aparece aqui com a mesma nitidez. A globalização e a urbanização fragmentada de condomínios e de shoppings e a promoção dos megaeventos não se verificam nas áreas estudadas com a mesma força e visibilidade que nos municípios centrais. Percebe-se sim a permanência da urbanização popular periférica superposta à turistificação do território, à valorização e especulação fundiária. Esses processos associam-se, também, à 'refuncionalização' das várias cidades e à integração regional dos mercados de trabalho, educacionais e de serviços, sobre os quais não falei neste trabalho, mas seria necessário fazê-lo numa outra oportunidade.

Certamente as sociabilidades presentes no transporte são limitadas por seu caráter de aventura, mas não se reduzem ao mínimo da cidade-passagem, ao menos, não no transporte informal e naquele intermediado por novos dispositivos. A comunicação que promovem e as formas espontâneas de cooperação personalizada de que aqui tratei como sociabilidade doméstica apontam para a existência de uma série de disposições e atitudes incorporadas, que tendem a recriar laços e relações. Quero dizer com isto que esta sociabilidade não se produz no transporte como resultado do mero ato de viajar, que, ao relacionar diversos atores e áreas (morais), estimula novos vínculos e a busca por referentes morais em comum. Ao longo da rede urbana relacionada, articulam-se antigas e novas centralidades numa rede não muito bem conhecida, sobre a qual se reordenam impessoalidade/cosmopolitismo e pessoalidade/proximidade numa nova geografia de sociabilidades. 0 que falta a estes processos é visibilidade e que se fale deles; que formem uma cultura ou culturas que articulem os lugares, em sequências, coletivamente reconhecidas, para além da vivência cotidiana, na circulação regional. 


\section{Referências}

AJARA, C; NETO, A. F. P. Transformações recentes na dinâmica sócio-espacial do Norte Fluminense. In: ENCONTRO NACIONAL DA ABEP, 15., 2006, Caxambu. Anais [...]. Disponível em: em https://royaltiesdopetroleo.ucam-campos.br/wp- content/uploads/2017/05/ABEP2006_795.pdf. Acesso em: 20 out. 2006.

CASTELLS, M.; BORJA, J. Local y Global: la gestión de las ciudades en la era de la información. Santillana: Taurus, 1997.

FRUGOLI JÚNIOR, H. Sociabilidade Urbana. Rio de Janeiro: Zahar, 2007.

GINZBURG, C. Sinais e Raízes de um paradigma indiciário. In: GINZBURG, C. Mitos, Emblemas e Sinais. Rio de Janeiro: Companhia das Letras, 1989. GOTTDINER, M. A produção Social do Espaço Urbano. Tradução de Geraldo Gerson de Souza. São Paulo: EDUSP, 1993.

GOTTMAN, Jean. Megalopolis: The Urbanized Northeastern Seaboard of the United States New York: The Twentie Nth Century Fund, 1961.

JOSEPH, I. Le droit à la ville, la ville à l'œuvre. Deux paradigmes de la recherche. Les Annales de la Recherche Urbaine, Année, n. 64, p. 5-10, 1994.

LAGO, L. C. do. A metrópole desigualmente integrada: as atuais formas de produção e não acesso ao espaço construído. In: ENCONTRO NACIONAL DA ANPUR, 9., 2001, Rio de Janeiro. Anais [...].

LAGO, L. C. do. Divisão Sócio-Espacial e Mobilidade Residencial: reprodução ou alteração das fronteiras espaciais? Rio de Janeiro: IPPUR/UFRJ, 2000.

LEFEBVRE, H. A Revolução Urbana. Belo Horizonte: Humanitas, 2002.

MAMANI, H. A. Usuário: Ator Ausente da Política de Transporte Fluminense:Estudo das Políticas e os Conflitos nas Cidades do Rio de Janeiro e Campos dos Goytacazes. 2017. (Projeto).

MAMANI, H. A. A Política Urbana e a Questão do Transporte: Estudo Comparativo Das Políticas Municipais em Relação ao transporte informal em Campos, Macaé e Rio das Ostras, a partir de 2000. 2016. (Relatório de Pesquisa)

MAMANI, H. A. Economia informal, mercado de trabalho e Políticas Públicas no Norte Fluminense. Relatório de Pesquisa. 2011.

MAMANI, H. A. Vida Metropolitana e Transporte Informal: estudo do Rio de Janeiro nos anos 90. 2004. Tese (Doutorado). Rio de Janeiro: IPPUR/ UFRJ 2004.

PARK, R. A Cidade: Programa de Investigação. In: VELHO, G. 0 Fenômeno Urbano Rio de Janeiro: Zahar, 1973.

QUEIROGA, E. F. A megalópole e a Praça: o espaço entre a razão e a dominação. 2001. São Paulo. Tese (Doutorado em Arquitetura e Urbanismo) FAUSP/USP, São Paulo, 2000.

RIBEIRO, A. C. Urbanização sem Urbanidade: um cenário de incertezas. Ensaios FEE, Porto Alegre, v. 16, n. 2, p. 556 -590, 1995.

SANTOS, M. Por uma Outra Globalização: do pensamento único à consciência emoção. São Paulo: HUCITEC, 2000.

SANTOS, M. A Natureza do Espaço: Técnica e Tempo Razão e emoção. São Paulo: HUCITEC, 1999.

SILVA, E. T.; CAVENAGHI, S. Mercado de trabalho e diferenciais por sexo em Campos dos Goytacazes e Macaé. In: Encontro Nacional da ABEP, 15., 2006, Caxambu, 2006. Anais [...]. Disponível em: http://www.abep.nepo.unicamp.br/encontro2006/docspdf/ABEP2006_795.pdf. Acesso em: 20 out.2006.

SIMMEL, G. A metrópole e a vida mental. In: VELHO, G. O Fenômeno Urbano. Rio de Janeiro: Zahar, 1973.

SIMMEL. G. A Aventura. In: SOUZA, Jessé; ÖELZE, Berthold. Simmel e a modernidade. Brasília: UnB,1998. p. 171-187. 